\title{
Limited, episodic diversification and contrasting phylogeography in a New Zealand cicada radiation
}

David C Marshall ${ }^{1 *}$, Kathy B R Hill ${ }^{1}$, Katharine A Marske ${ }^{2,3}$, Colleen Chambers ${ }^{1}$, Thomas R Buckley $3,4,5$ and Chris Simon ${ }^{1,6}$

\begin{abstract}
Background: The New Zealand (NZ) cicada fauna contains two co-distributed lineages that independently colonized the isolated continental fragment in the Miocene. One extensively studied lineage includes $90 \%$ of the extant species (Kikihia + Maoricicada + Rhodopsalta; ca 51 spp.), while the other contains just four extant species (Amphipsalta -3 spp. + Notopsalta - 1 sp.) and has been little studied. We examined mitochondrial and nuclear-gene phylogenies and phylogeography, Bayesian relaxed-clock divergence timing (incorporating literature-based uncertainty of molecular clock estimates) and ecological niche models of the species from the smaller radiation.
\end{abstract}

Results: Mitochondrial and nuclear-gene trees supported the monophyly of Amphipsalta. Most interspecific diversification within Amphipsalta-Notopsalta occurred from the mid-Miocene to the Pliocene. However, interspecific divergence time estimates had large confidence intervals and were highly dependent on the assumed tree prior, and comparisons of uncorrected and patristic distances suggested difficulty in estimation of branch lengths. In contrast, intraspecific divergence times varied little across analyses, and all appear to have occurred during the Pleistocene. Two large-bodied forest taxa (A. cingulata, A. zelandica) showed minimal phylogeographic structure, with intraspecific diversification dating to ca. 0.16 and $0.37 \mathrm{Ma}$, respectively. MidPleistocene-age phylogeographic structure was found within two smaller-bodied species (A. strepitans - $1.16 \mathrm{Ma}$, $N$. sericea - 1.36 Ma] inhabiting dry open habitats. Branches separating independently evolving species were long compared to intraspecific branches. Ecological niche models hindcast to the Last Glacial Maximum (LGM) matched expectations from the genetic datasets for $A$. zelandica and A. strepitans, suggesting that the range of $A$. zelandica was greatly reduced while $A$. strepitans refugia were more extensive. However, no LGM habitat could be reconstructed for $A$. cingulata and $N$. sericea, suggesting survival in microhabitats not detectable with our downscaled climate data.

Conclusions: Unlike the large and continuous diversification exhibited by the Kikihia-Maoricicada-Rhodopsalta clade, the contemporaneous Amphipsalta-Notopsalta lineage contains four comparatively old (early branching) species that show only recent diversification. This indicates either a long period of stasis with no speciation, or one or more bouts of extinction that have pruned the radiation. Within Amphipsalta-Notopsalta, greater population structure is found in dry-open-habitat species versus forest specialists. We attribute this difference to the fact that NZ lowland forests were repeatedly reduced in extent during glacial periods, while steep, open habitats likely became more available during late Pleistocene uplift.

\footnotetext{
* Correspondence: david.marshall@uconn.edu

'Department of Ecology and Evolutionary Biology, University of Connecticut,

75 N. Eagleville Rd, Storrs, CT 06269, USA

Full list of author information is available at the end of the article
}

\section{Biomed Central}

(c) 2012 Marshall et al.; licensee BioMed Central Ltd. This is an Open Access article distributed under the terms of the Creative Commons Attribution License (http://creativecommons.org/licenses/by/2.0), which permits unrestricted use, distribution, and reproduction in any medium, provided the original work is properly cited. 


\section{Background}

The cicadas of New Zealand (NZ) present an example of rapid ecological radiation in response to landscape and climate changes, mainly of the Pliocene $(5.3-2.6 \mathrm{Ma})$ and Pleistocene (2.6 - $0.1 \mathrm{Ma})$ epochs [1-3]. Approximately $55 \mathrm{NZ}$ species form two monophyletic groups, each derived from an overwater colonization event $[4,5]$. Most belong to a large clade containing three genera: Kikihia Dugdale (ca. 28 taxa), Maoricicada Dugdale (ca. 20 taxa), and Rhodopsalta Dugdale (3 taxa), which are related to New Caledonian cicadas [4,5]. Species of this clade are distributed across all three main islands (North, South, Stewart; see Figure 1 and Figure 2) and several outer islands, and together they inhabit a variety of low- and mid-elevation habitats [6-9]. The diversification of Maoricicada, in particular, is an extraordinary case for the family Cicadidae because its species are largely alpine in distribution. Molecular-clock studies suggest that diversification in both Kikihia and Maoricicada began around 6-7 Ma and accelerated through the Pliocene as mountain-building increased temperature and moisture contrasts throughout $\mathrm{NZ}$ and isolated populations geographically $[1,2,10]$.

The remaining NZ cicada species (two genera) belong to the same tribe (Cicadettini) but form a separate monophyletic clade related to Australian taxa $[4,5]$. This clade is also widely distributed across NZ and includes

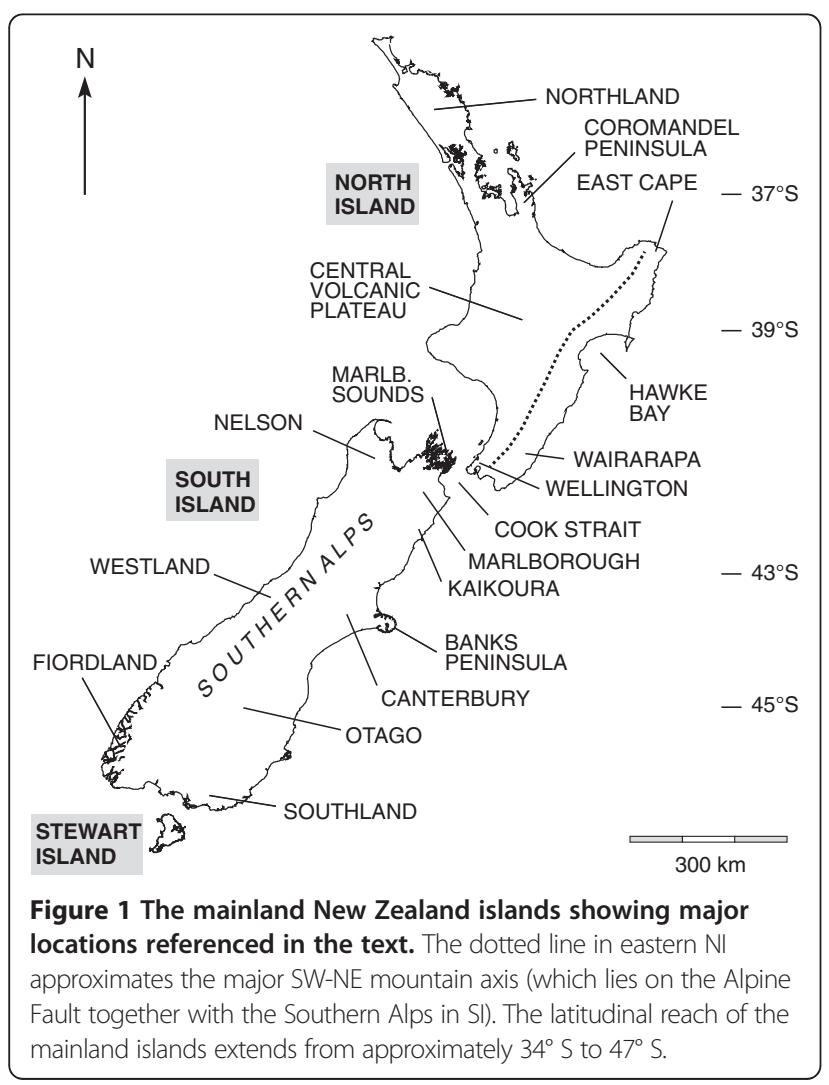

the familiar wing-clapping Amphipsalta Fleming species. However, these species have received comparatively little study. Amphipsalta zelandica (Boisduval) inhabits low- to mid-elevation forests throughout mainland $\mathrm{NZ}$ and nearby islands, while $A$. cingulata (Fabricius) is found only on North Island (NI), mainly in trees of coastal scrub habitats [11] (Figure 2). A. strepitans (Kirkaldy) utilizes shrubs (Discaria, Cassinia - [11]) in dry, open habitat, and it sings on both vegetation and rocks [12,13] from southern NI to southeastern South Island (SI). Notopsalta sericea (Walker) sings from vegetation, volcanic rocks, and clay banks in steep, open country [13] throughout NI. The small size of the Amphipsalta-Notopsalta radiation is remarkable because its ancestor arrived in NZ at approximately the same time as the Kikihia-Maoricicada-Rhodopsalta ancestor, and because it likely experienced similar Miocene and Pleistocene landscape and climate changes [14,15].

In this study we use multi-gene molecular-phylogenetic methods, divergence-time analysis, intraspecific sampling, and ecological niche models (ENMs) to examine the evolution of Amphipsalta-Notopsalta. We find that few extant lineages in the clade originated during the late Miocene and Pliocene, either because speciation rates were then low or because most lineages appearing during that time later went extinct. In addition, we find evidence of Pleistocene-age intraspecific diversification with contrasting phylogeographic histories across the species. Species' modeled geographic ranges at the LGM (Last Glacial Maximum, c. 22,000 cal yrs BP) varied from distributions similar to at present to entirely absent at the LGM refugia.

\section{Results}

Maximum-likelihood phylogenetic and phylogeographic relationships

All sequences were submitted to GenBank under accession numbers JX675238 - JX675427 (COI), JX675449 JX675465 (Calmodulin), and JX675428 - JX675448 (EF-1 $\alpha$ ). Character profiles and partition-specific models selected are shown in Table 1. The two nuclear loci were characterized by low numbers of parsimony-informative sites among ingroup taxa. The absence of a gamma parameter in the Modeltest output for those genes indicates either a simple pattern of among-site rate variation, or insufficient data for estimation of a more complex model. PartitionFinder identified support for a three-partition mtDNA model (with each codon position modeled separately).

COI sequences of the four species formed strongly supported monophyletic groups, and Amphipsalta was recovered as a monophyletic group (91\% ML bootstrap), but $A$. zelandica and $A$. cingulata were only weakly supported as sister-taxa (Figure 3 ). COI patristic genetic distances between the four species ranged from 0.21-0.31 substitutions/site (uncorrected $p$ distance 0.061-0.082). 


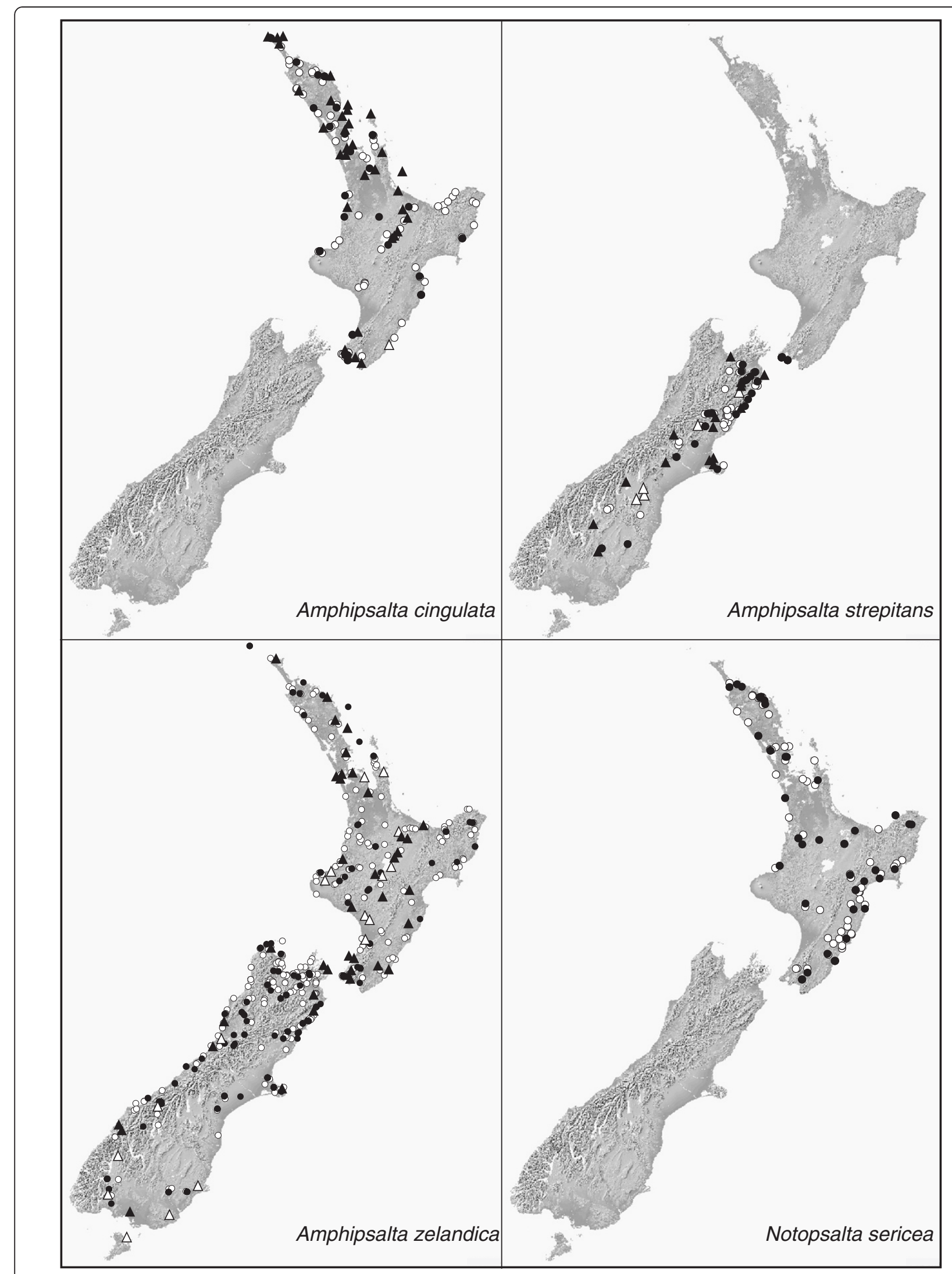

Figure 2 Distributions of the Amphipsalta and Notopsalta species. Records are based on C. Simon lab (circles) and Dugdale and Fleming [11] (triangles) observations, plotted on a shaded elevation map. Filled symbols indicate collected specimens; open symbols represent song records only. 
The nuclear-gene trees agreed with each other and with the COI topology, and they also supported a monophyletic Amphipsalta (>70\%). A. cingulata and A. zelandica were supported as sister-species with $>70 \%$ ML bootstrap support in both nuclear gene trees (Figure 3).

Phylogeographic structure was evident within all species, but with considerable differences in levels of divergence. Little intraspecific divergence (weak structure) in COI was detected for either A. cingulata or A. zelandica. Maximum patristic genetic distances between haplotypes from the partitioned ML analysis (Figure 3) were 0.005 substitutions/site (s/s) in A. cingulata (0.004 uncorrected, or $p$ distance) and $0.011 \mathrm{~s} / \mathrm{s}$ (0.009 uncorrected) in $A$. zelandica. For both species, haplotype patterns suggested a north-south phylogeographic break within NI, especially in $A$. zelandica, where a distinctive haplotype cluster was limited to northern NI (ML bootstrap 64\%).

ML patristic distances within $A$. strepitans and $N$. sericea were 3-6 times greater, with obvious geographical patterning (Figure 3). Within A. strepitans, haplotypes from southern SI differed by up to $0.04 \mathrm{~s} / \mathrm{s}(0.024 p$ distance) from haplotypes in central NZ. The lone N. sericea haplotype from southwestern NI differed from other $N$. sericea haplotypes by $0.038 \mathrm{~s} / \mathrm{s}$ in COI $(0.025 p$ distance). $N$. sericea haplotypes along the eastern coast formed geographically coherent sister-clades, and haplotypes from the northern NI were nearly genetically identical (Figure 3). Otherwise, the phylogenetic relationships between regional haplotype clusters were poorly resolved in both $N$. sericea and $A$. strepitans.

The comparatively limited EF- $1 \alpha$ dataset mirrored some intraspecific patterns observed in COI. EF- $1 \alpha$ sequences for $A$. zelandica and $A$. cingulata were nearly identical within species, as for COI. Within A. strepitans, the central Otago sequence was divergent from the rest, and the Wellington (southern NI) and Marlborough (northern SI) samples were sister to one another. The $N$. sericea EF- $1 \alpha$ sequences yielded the same three-way split observed between southwestern, eastern, and northern NI.

Intraspecific relationships observed in the calmodulin dataset generally did not match those found in COI and EF-1 $\alpha$. Notably, no sequence divergence was observed between the four $N$. sericea specimens even though these individuals were highly divergent at the other two loci. Two divergent haplotypes (mostly differing at a gene section containing tandem repeats) were found for $A$. cingulata, but little genetic divergence for COI or EF-1 $\alpha$ was observed for individuals possessing those haplotypes. Differences in phylogenetic signal between calmodulin and EF-1 $\alpha / \mathrm{mtDNA}$ have been detected in other NZ cicada species, with calmodulin divergence rates much higher for some species than for their congeners [16].

\section{Intraspecific diversification}

The GMYC algorithm identified independent lineages within each of the four described species (Additional file 1: Figure S1) - six in Amphipsalta zelandica, two in A. cingulata, seven in A. strepitans, and four in Notopsalta sericea; the null hypothesis was rejected by a likelihood-ratio test (null likelihood =238.2016; GMYC likelihood $=246.8606 ; P<0.006)$. However, results were dependent on the dataset used. When A. zelandica and A. cingulata haplotypes were removed to see if their low intraspecific divergence was pulling the between/ within-species threshold closer to the present, the GMYC algorithm diagnosed nearly every haplotype of the remaining species as an independent population lineage, although the results were only marginally significant (null likelihood $=141.2776$, GMYC likelihood $=$ 145.5174, $P<0.037$ ). AMOVA results (Table 2) indicated considerable geographic-genetic structure, with greater than $30 \%$ of the genetic variance explained at the regional level in each species. Amphipsalta strepitans and $N$. sericea exhibited the highest levels of genetic variance between regions.

\section{Pairwise genetic divergence plots}

The relationships between corrected (patristic) and uncorrected mtDNA distances for Amphipsalta-Notopsalta (this study) and for Kikihia COI + COII sequences [1] were similar only at low genetic distances (Figure 4). For both datasets, this relationship was curved upward only slightly at low uncorrected genetic distances. At greater distances, the relationships diverged. Despite the fact that maximum uncorrected divergence levels were similar for the two datasets (ca. 8\%), the maximum patristic distances were $0.22 \mathrm{~s} / \mathrm{s}$ in Kikihia and $0.31 \mathrm{~s} / \mathrm{s}$ in Amphipsalta-Notopsalta (Figure 4). The AmphipsaltaNotopsalta curve was notably ragged at high genetic distances, with substantially different patristic distances reconstructed for some taxa with uncorrected distances greater than $6 \%$.

\begin{tabular}{|c|c|c|c|c|}
\hline Gene/partition & \# Sites & $\begin{array}{l}\text { \# Variable } \\
\text { sites }\end{array}$ & $\begin{array}{l}\text { \# Parsimony } \\
\text { informative }\end{array}$ & $\begin{array}{l}\text { Model } \\
\text { selected }\end{array}$ \\
\hline $\mathrm{COI}\left(1^{\text {st }} \text { pos. }\right)^{*}$ & 451 & 21 & 16 & $\operatorname{TrN}+1$ \\
\hline $\mathrm{COI}\left(2^{\text {nd }} \text { pos. }\right)^{*}$ & 451 & 5 & 4 & F81 \\
\hline $\mathrm{COI}\left(1^{\text {st }}+2^{\text {nd }}\right.$ pos. $)$ & 902 & 26 & 20 & $H K Y+G$ \\
\hline $\mathrm{COI}\left(3^{\text {rd }} \text { pos. }\right)^{*}$ & 451 & 203 & 184 & $\mathrm{TIM}+\mathrm{G}$ \\
\hline COI (all sites) & 1353 & 229 & 204 & $G T R+I+G$ \\
\hline Calmodulin & 719 & 44 & 29 & $\mathrm{TIM}+\mathrm{I}$ \\
\hline EF-1a & 1304 & 69 & 56 & $H K Y+I$ \\
\hline
\end{tabular}




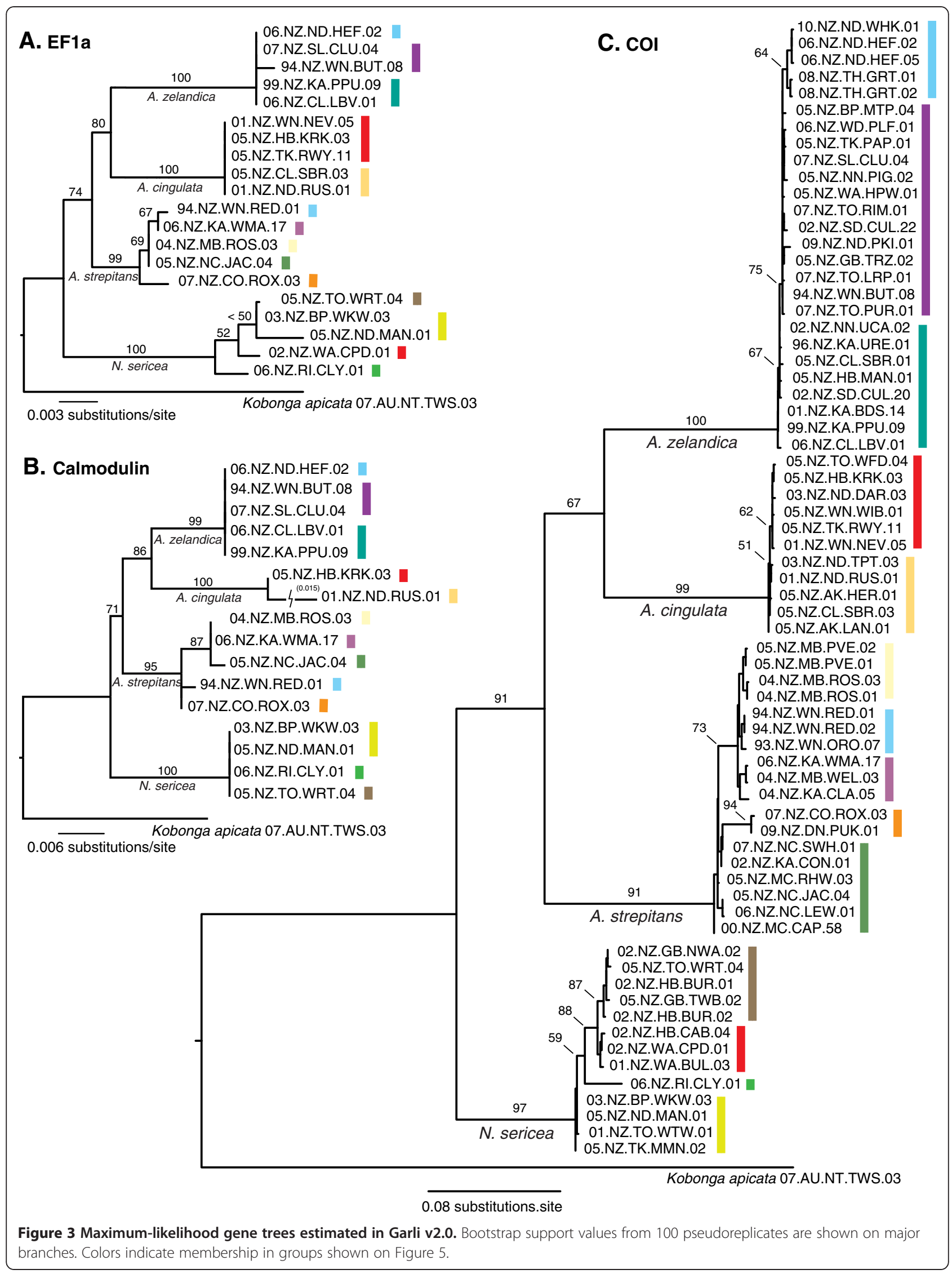




\begin{tabular}{|c|c|c|c|c|}
\hline Source of variation & d.f. & $\begin{array}{l}\text { Sum of } \\
\text { squares }\end{array}$ & $\begin{array}{l}\text { Variance } \\
\text { components }\end{array}$ & $\begin{array}{l}\text { Percentage } \\
\text { of variation }\end{array}$ \\
\hline A. cingulata & $F_{s t}=1.00000$ & & & \\
\hline Among regions & 2 & 10.371 & 0.47420 & $34.35^{*}$ \\
\hline Among populations within regions & 17 & 18.829 & 0.90615 & $65.65^{*}$ \\
\hline Within populations & 5 & 0.000 & 0.00000 & $0.00^{*}$ \\
\hline Total & 24 & 29.200 & 1.38035 & \\
\hline A. zelandica & $F_{s t}=0.53778$ & & & \\
\hline Among regions & 5 & 50.856 & 0.49576 & $28.74^{*}$ \\
\hline Among populations within regions & 69 & 98.313 & 0.43187 & $25.04^{*}$ \\
\hline Within populations & 37 & 29.500 & 0.79730 & $46.22^{*}$ \\
\hline Total & 111 & 178.670 & 1.72492 & \\
\hline A. strepitans & $F_{s t}=0.98929$ & & & \\
\hline Among regions & 3 & 100.958 & 4.20935 & $40.56^{*}$ \\
\hline Among populations within regions & 11 & 100.167 & 6.05782 & $58.37^{*}$ \\
\hline Within populations & 9 & 1.000 & 0.11111 & $1.07^{*}$ \\
\hline Total & 23 & 202.125 & 10.37829 & \\
\hline N. sericea & $F_{s t}=0.83766$ & & & \\
\hline Among regions & 2 & 54.042 & 2.51745 & $40.87^{*}$ \\
\hline Among populations within regions & 32 & 87.958 & 2.64237 & 42.90 \\
\hline Within populations & 2 & 2.000 & 1.00000 & 16.23 \\
\hline Total & 27 & & & \\
\hline
\end{tabular}

${ }^{1}$ Regions were defined by a six-way, north-to-south partition of the NZ mainland. Asterisks indicate statistically significant tests $(p<0.05)$.

\section{Divergence-time analysis}

The BEAST analyses under different tree models showed a strong effect of the prior on interspecific divergence times, but comparatively little effect on intraspecific haplotype divergences and species' MRCA ages (Table 3). The birth-death model resulted in a mean root age of 24.45 Ma, compared to only 4.82 $\mathrm{Ma}$ for the Yule and approximately $17 \mathrm{Ma}$ for each of the two coalescent models. Intraspecific divergences were dated to the Pleistocene in all cases. Analyses run with no data in order to estimate the prior returned divergence times close to zero for all nodes.

While the estimated marginal likelihoods were similar for the birth-death, constant-size coalescent, and expansion-growth coalescent models, the $2 \ln$ Bayes factor score indicated support for the birth-death model (Table 4). Under this model, the Amphipsalta + Notopsalta ancestor diverged from the outgroup approximately $24 \mathrm{Ma}$, and Notopsalta split from the Amphipsalta common ancestor at around $12.5 \mathrm{Ma}$. The remaining interspecific divergences were dated to ca. $9 \mathrm{Ma}$ (A. strepitans) and $7 \mathrm{Ma}$ (A. cingulata - A.zelandica split) (Figure 5). The earliest splits within $A$. strepitans and $N$. sericea dated to the mid-Pleistocene (ca. 1.2 Ma and 1.4 Ma, respectively), while splits within $A$. zelandica and $A$. cingulata dated to the Late Pleistocene (mean ca. 0.4 and 0.2 Ma, respectively). Credible intervals for the intraspecific coalescences were similar in magnitude (relative to the mean estimates) to those observed for the interspecific splits (Table 3$)$. The meanrate estimate $(0.012 \mathrm{~s} / \mathrm{s})$, reflecting the mean clock rate across the tree, remained close to the fixed ucld.mean rate, as expected because no calibrations other than the fixed values for ucld.mean and ucld.stdev were used in the analysis. Because we fixed ucld.stdev, we could not use this statistic to test for clocklike evolution, but because clocklike data can be accommodated by a relaxed clock model our approach is conservative.

The maximum clade compatibility tree from the BEAST analysis (Figure 5) found different intraspecific root positions for $N$. sericea and A. strepitans, compared to the ML results. As a result, some geographically coherent haplotype clades that appeared paraphyletic in the ML tree were found to be monophyletic with strong support (> 90\% posterior probability) in the BEAST analysis.

\section{Ecological niche models}

Bioclimatic models of the distribution of Amphipsalta zelandica yielded an average AUC of 0.806 (s.d. 0.036) in the 10-fold cross-validation runs and performed significantly better than random $(P<0.05)$ in the binomial 

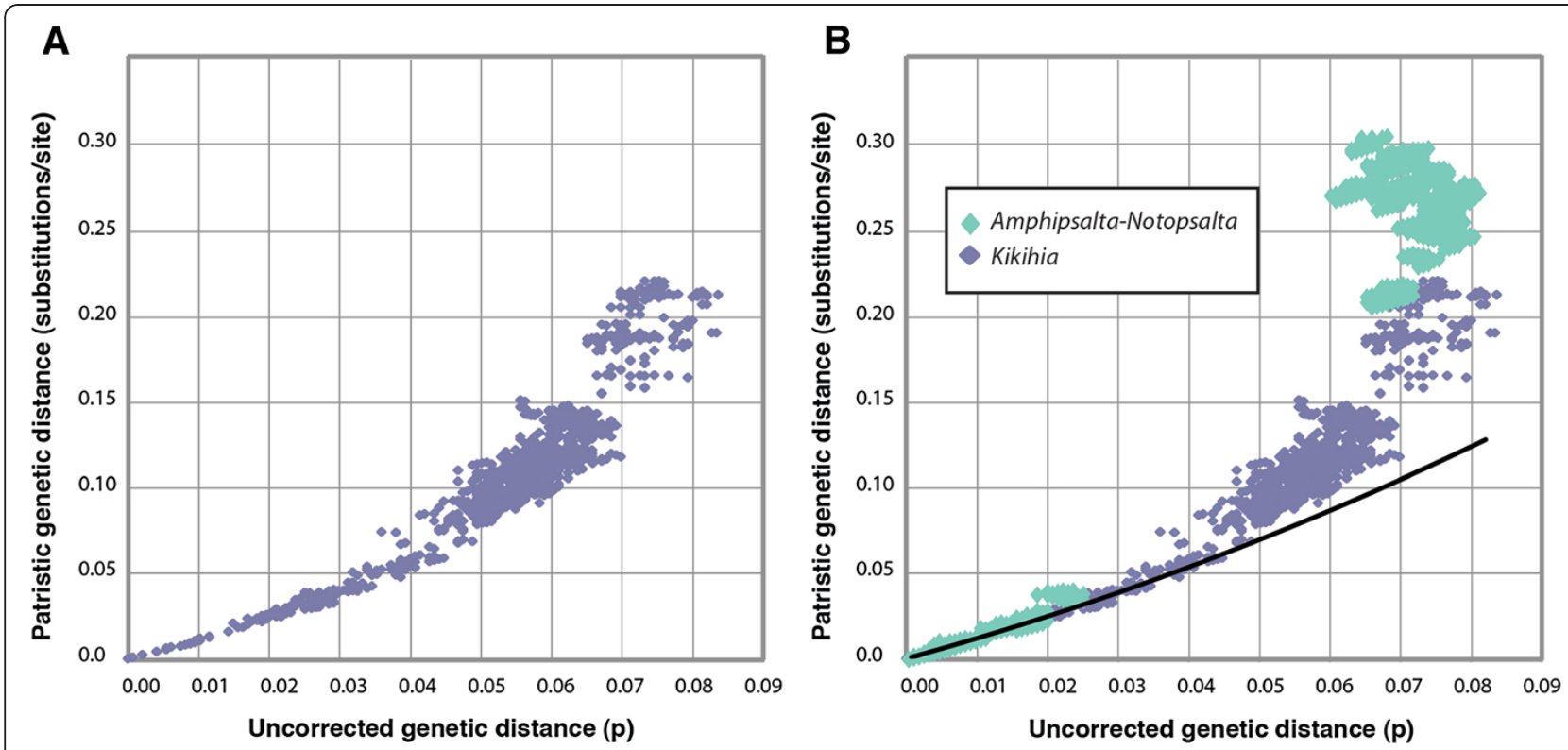

Figure 4 Plots of mtDNA uncorrected distance vs. ML patristic distance. A) Plot from a well-sampled Kikihia COI + COII mtDNA ingroup dataset containing 30 species [1]. B) Plot from the Amphipsalta-Notopsalta COI dataset from this study (light green dots), superimposed on the plot from $\mathrm{A}$. The datasets span a nearly identical range of uncorrected distance values, but many corrected pairwise distances are over twice as large for Amphipsalta-Notopsalta at uncorrected distances $>6 \%$. The trendline in B was fitted to the Kikihia data points under $4 \%$ uncorrected distance.

omission tests across all thresholds and runs. Heuristic estimation of relative contributions of the environmental variables indicated that annual temperature (38.9\%) and February temperature (20.5\%) were the top predictors of the distribution of A. zelandica. Effects of clamping during LGM projection were minor and restricted to montane areas. Under current climate conditions, A. zelandica was projected to be widely distributed throughout NI and northern SI in lowland regions (Figure 6). During the LGM, most of NZ was projected as less suitable for $A$. zelandica, with the exception of the Coromandel Peninsula and East Cape in northern NI and Karamea, Central Nelson and Kaikoura in northern SI (Figure 6).

Models for the distribution of A. strepitans also performed significantly better than random in the binomial omission tests in all but one run and yielded an average AUC of 0.940 (s.d. 0.054) (note that AUC values tend to be higher for geographically restricted taxa). The top predictor of the distribution of $A$. strepitans was October vapor pressure deficit (87.1\%), with February temperature a distant second (4.4\%). Effects from clamping during LGM projection were largely restricted to the central Southern Alps. The species' projected distribution centered on the northeastern SI, particularly the coastal Kaikoura Ranges (Figure 6), under both climate scenarios, and the projected LGM distribution was slightly larger (more area with suitability $>0.5$ ) than that for current conditions. Notably, the model failed to capture the southern extent of the species' range - several sampled populations fall within the region of $0-10 \%$ probability predicted by Maxent. As this may have been due to the high number of localities from the northern SI, resulting in over-fitting of regional conditions, input localities for $A$. strepitans were thinned to a minimum distance of $5 \mathrm{~km}$ apart (removing 15 localities from the

Table 3 Mean divergence-time estimates (in Ma) and 95\% confidence intervals from BEAST analyses using different tree models

\begin{tabular}{llllllll}
\hline Tree model & root & $\begin{array}{l}\text { Amphipsalta- } \\
\text { Notopsalta }\end{array}$ & Amphipsalta & $\begin{array}{l}\text { N. sericea } \\
\text { MRCA }\end{array}$ & $\begin{array}{l}\text { A. strepitans } \\
\text { MRCA }\end{array}$ & $\begin{array}{l}\text { A. zelandica } \\
\text { MRCA }\end{array}$ & $\begin{array}{l}\text { A. cingulata } \\
\text { MRCA }\end{array}$ \\
\hline Yule & $4.82(3.87-5.69)$ & $3.70(2.95-4.49)$ & $2.97(2.42-3.56)$ & $1.01(0.64-1.39)$ & $0.84(0.60-1.11)$ & $0.39(0.26-0.54)$ & $0.23(0.13-0.34)$ \\
birth-death & $24.45(14.86-38.10)$ & $12.59(7.6-17.2)$ & $9.22(5.75-12.82)$ & $1.36(0.70-2.06)$ & $1.16(0.66-1.70)$ & $0.37(0.19-0.56)$ & $0.16(0.06-0.27)$ \\
coalescent (constant) & $17.43(11.11-23.97)$ & $8.21(5.67-10.69)$ & $5.91(4.04-7.61)$ & $1.28(0.75-1.87)$ & $1.07(0.65-1.44)$ & $0.39(0.22-0.59)$ & $0.18(0.08-0.28)$ \\
coalescent (expansion) & $17.00(10.70-23.42)$ & $8.13(5.64-10.35)$ & $5.85(4.20-7.59)$ & $1.26(0.77-1.89)$ & $1.07(0.68-1.52)$ & $0.39(0.23-0.59)$ & $0.18(0.08-0.30)$
\end{tabular}

Estimates of interspecific divergence times were strongly influenced by the tree prior, while ages of species' MRCAs and intraspecific divergences varied much less. 


\begin{tabular}{|c|c|c|c|c|c|c|}
\hline \multirow[t]{2}{*}{ Tree model } & \multirow{2}{*}{$\begin{array}{l}\text { estimated } \\
\text { mean }-\ln L\end{array}$} & \multirow[t]{2}{*}{ S. E. } & \multicolumn{4}{|c|}{2 (In Bayes factor score) } \\
\hline & & & vs. Yule & vs. birth-death & $\begin{array}{l}\text { vs. coalescent } \\
\text { (constant size) }\end{array}$ & $\begin{array}{c}\text { vs. coalescent } \\
\text { (expansion) }\end{array}$ \\
\hline Yule & -4236.94 & \pm 2.085 & - & -179.978 & -160.334 & -157.378 \\
\hline birth-death & -4146.95 & \pm 1.191 & 179.978 & - & 19.644 & 22.602 \\
\hline coalescent (constant size) & -4156.77 & \pm 1.113 & 160.334 & -19.644 & - & 2.956 \\
\hline coalescent (expansion) & -4158.25 & \pm 0.912 & 157.378 & -22.602 & -2.956 & - \\
\hline
\end{tabular}

Strong support for the birth-death model was indicated, according to the criterion 2 In Bayes factor $>10$.

northern SI) and modeled again as above. The resulting models were no better at capturing the southern extent of the species' distribution (data not shown), which is represented by only 5 localities south of central Canterbury.

Results for Notopsalta sericea were also significantly better than random, with only one threshold for one run yielding $P>0.05$ in the binomial omission tests, and an average AUC of 0.874 (s.d. 0.031). Top climatic predictors were February temperature $(55.9 \%)$ and minimum temperature (23.8\%), and no effects from clamping were detected during projection. Under modern conditions, northern and coastal NI were projected as climatically suitable, but none of $\mathrm{NZ}$ was projected to contain suitable conditions during the LGM (Figure 6).

Models for A. cingulata yielded similar geographic projections, with much of lowland NI projected as climatically suitable under modern conditions, and no refugia projected for the LGM (Figure 6). Results from the binomial omission tests were significantly different from random except for one data partition which yielded multiple thresholds with $P>0.5$. The average AUC across ten runs was 0.881 (s.d. 0.043), and annual temperature $(73.2 \%)$ and minimum temperature $(11.0 \%)$ were the top predictors of the distribution of $A$. cingulata.

When model calibration for $N$. sericea and A. cingulata was restricted to environmental conditions from NI, performance markedly declined, yielding average AUCs of 0.732 (s.d. 0.089) and 0.727 (s.d. 0.102), respectively, and multiple binomial omission tests for multiple runs yielded $P>0.05$. Areas of uncertainty (clamping) appeared when projecting onto the full LGM surface, and once these areas were removed, no likely refugia were detected, although some regions had climatic suitability above zero (Figure 6).

\section{Discussion}

Molecular clocks and divergence-time estimation for the Amphipsalta-Notopsalta radiation Molecular clock calibration and substitution models Insect molecular-clock studies often apply a mtDNA calibration of $2.3 \%$ pairwise distance per my, or 0.0115 substitutions/site/my/lineage, derived by Brower [17].
However, two estimates used by Brower were revised downward during re-analysis [18-20], and the remaining data were derived from rRNA, DNA-DNA hybridization, or RFLP datasets, so their applicability to mtDNA protein coding genes such as COI is unclear. In addition, none of the data used in the Brower study were corrected for multiple hits with data partitioning or the use of gamma-distributed rates, as most data are today [2124]. If studies that calibrate molecular clocks do not correct for multiple hits as thoroughly as the analyses that employ them, the date estimates will be biased [25].

The Bayesian relaxed-clock approach in BEAST allows the investigator to conservatively accommodate a range of plausible COI clock values with a single prior probability distribution in each analysis. We calibrated our analyses with fixed values for the mean branch rate and the standard deviation of that mean across the tree (ucld.mean and ucld.stdev parameters), set such that the 95\% credible intervals included the published rates cited in Table 5.

The divergence-time and ML analyses in this study may have suffered from poor branch-length estimation (with "branch lengths" estimated as rate $\mathrm{x}$ time products in the case of BEAST), perhaps related to the limited number of deep splits in the tree. Results from the BEAST analyses, specifically the ages of the interspecific splits, were strongly influenced by the choice of tree prior (Table 3). Plots of corrected vs. patristic distances in the Amphipsalta-Notopsalta and published Kikihia datasets showed that corrected distances were considerably greater for Amphipsalta-Notopsalta at the deepest levels examined, although both plots initially followed similar trajectories (Figure 4). Although the two datasets may have evolved under different mechanisms, the magnitude of the difference and the ragged nature of the Amphipsalta-Notopsalta plot are causes for concern. Further examination of the relationships between tree shape, dataset information, and branch lengths in maximumlikelihood and divergence-time analyses would likely prove useful. Notably, the confidence intervals on the intraspecific data estimates from BEAST were much narrower and largely unaffected by the tree prior. 


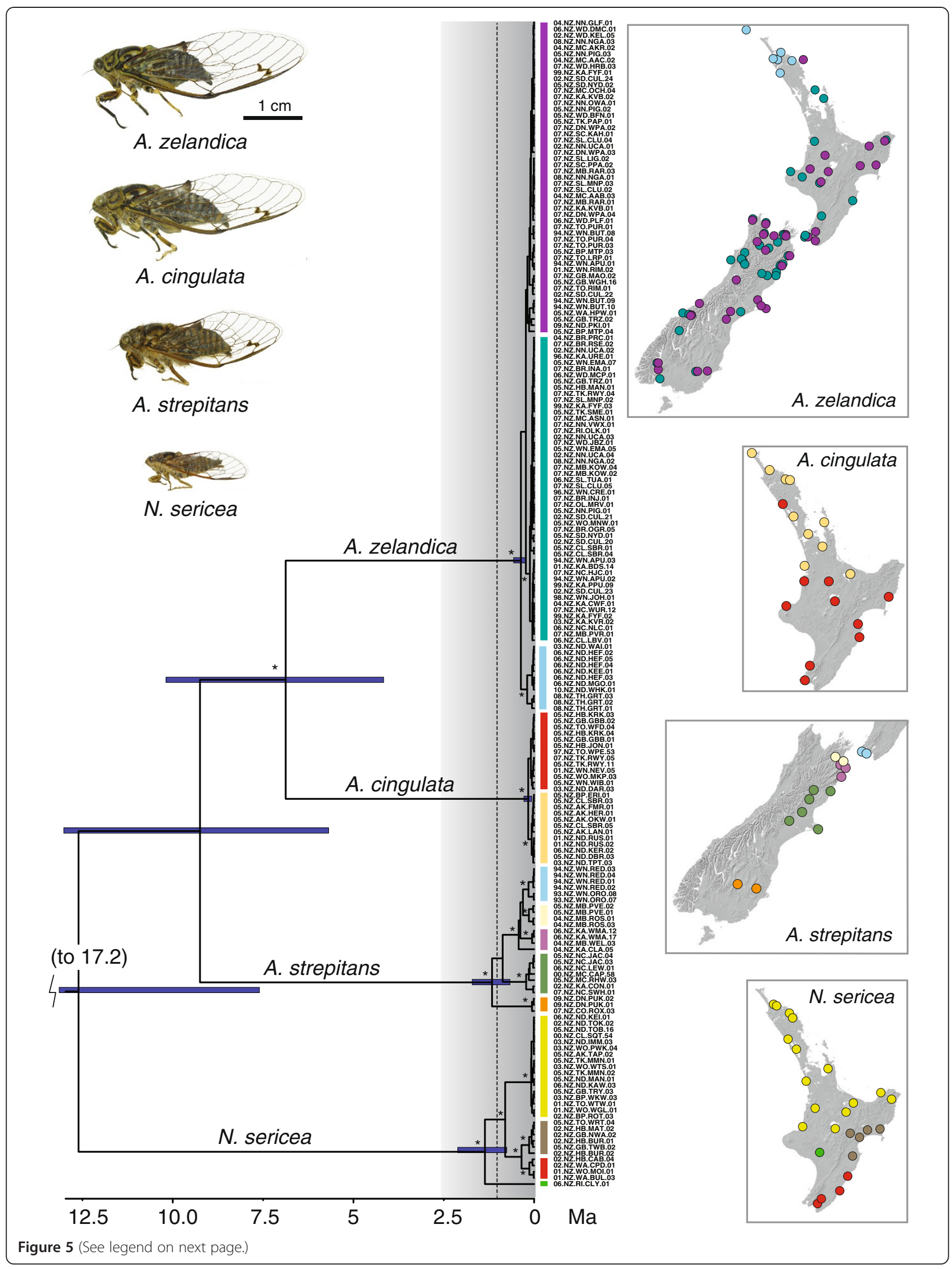


(See figure on previous page.)

Figure 5 BEAST v 1.6.1 relaxed-clock chronogram (maximum clade compatibility tree, with mean node ages calculated), with outgroup taxon and branches pruned. Tree was constructed using the Amphipsalta-Notopsalta mtDNA COI dataset and calibrated using literature

estimates of per lineage molecular clock rates in insects. Asterisks indicate major branches with $>90 \%$ posterior probability. Horizontal blue bars indicate $95 \%$ credible intervals on the mean divergence time estimates. Major haplotype groups are shown, by color, on the accompanying maps of the NZ landscape. Shading represents climatic deterioration during the Pleistocene, and the vertical dotted line represents accelerated uplift in northern $\mathrm{NZ}$ around $1 \mathrm{Ma}$.

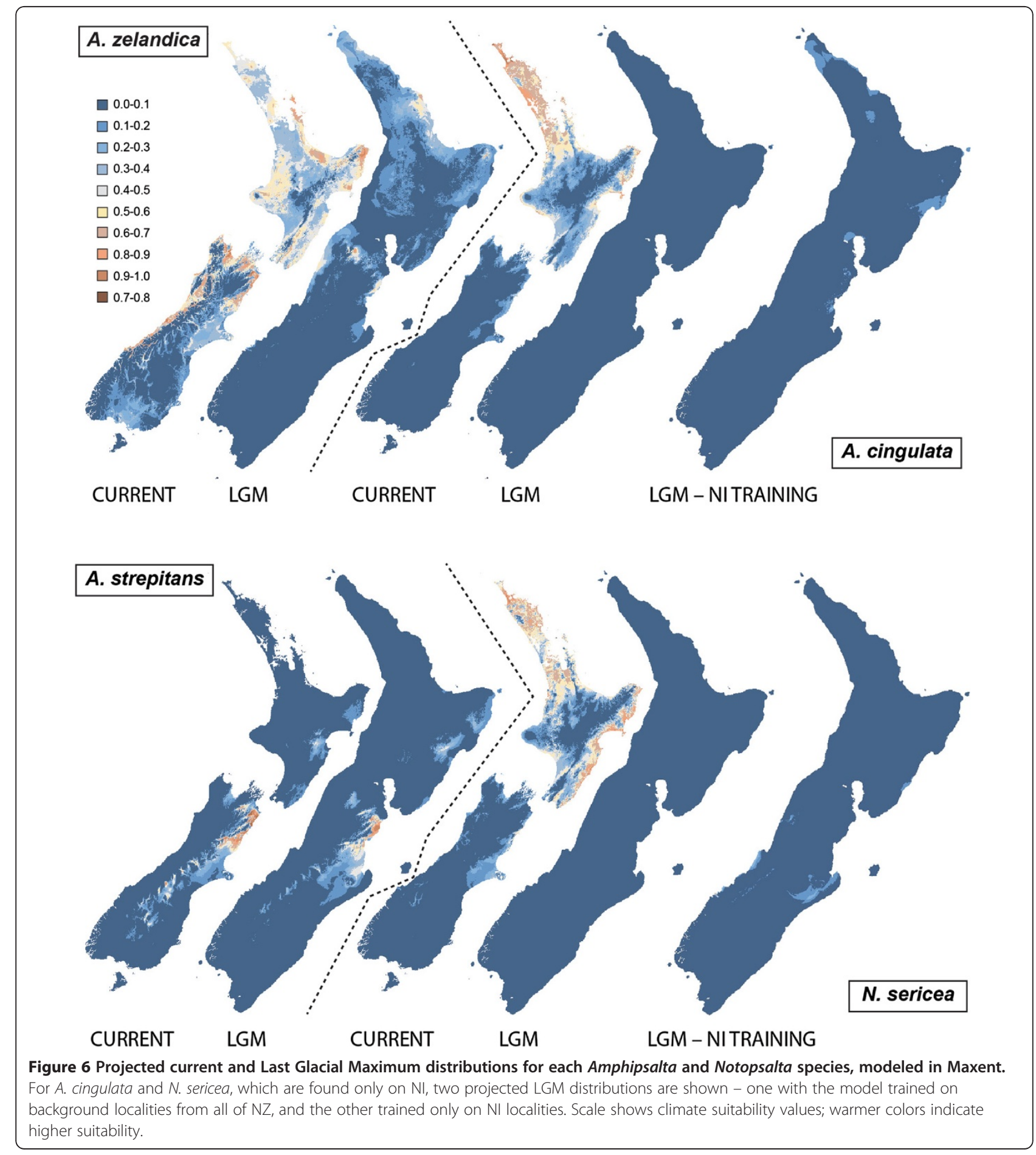


Table 5 Published arthropod substitution rate estimates for the mitochondrial gene cytochrome oxidase subunit I (COI)

\begin{tabular}{llll}
\hline Reference & Taxon & $\begin{array}{l}\text { Corrected pairwise } \\
\text { distance (\%) }\end{array}$ & $\begin{array}{l}\text { Per lineage rate, } \\
\text { (subst./site/my) }\end{array}$ \\
\hline Caccone and Sbordoni [95] & Ovobathysciola cave beetles & 1.2 & 0.006 \\
Caccone and Sbordoni [95] & Speonornus cave beetles & 1.3 & 0.0065 \\
Farrell [19] & Tetraopes beetles & 1.5 & 0.0075 \\
Juan et al. [96] & Pimelia beetles, Canary Is. & 1.3 & 0.0065 \\
Knowlton and Weigt [20], Morrison et al. [97] & Alpheus snapping shrimp & 1.4 & 0.007 \\
Papadopoulou et al. [25] & Tenebrionid beetle genera (6) & 3.54 & 0.0177 \\
Schubart et al. [98] & Sesarma land crabs \#1 & $1.28,1.9$ & $0.0064,0.0095$ \\
Sota and Hayashi [85] & Plateumaris leaf beetles & 1.6 & 0.008 \\
\hline
\end{tabular}

Although these distances were reported as percentages in the papers referenced, a common practice, this is not ideal for corrected distances since the values can exceed $100 \%$.

\section{Interspecific vs. intraspecific divergence timing}

Unlike the NZ Kikihia-Maoricicada-Rhodopsalta cicada radiation, the Amphipsalta-Notopsalta radiation contains no described species with Pleistocene origins. An earlier genus-level phylogenetic analysis including $A$. cingulata and $N$. sericea demonstrated a high level of genetic divergence between these species, consistent with a late Miocene to early Pliocene split (ca. 5-6 Ma) [5]. We find here that all interspecific divergences in the clade predate the Pleistocene (i.e., > 2.6 Ma), although these dates are uncertain. In addition, the low number of species in the Amphipsalta-Notopsalta radiation is not due to more recent diversification, since the earliest divergences of both clades appear to have occurred in the mid-Miocene [2,5]. (Due to extensive collecting over multiple decades, undiscovered extant species are unlikely.)

Although species-level diversification apparently preceded the Pleistocene, the genetic data suggest that several independently evolving, morphologically cryptic populations have formed during that period. All four species contain mtDNA phylogeographic structure, i.e., unique haplotypes or haplotype clusters occupying exclusive geographic ranges, with uncorrected genetic distances between clades approaching 2.5\%. The nuclear data show some concordant patterns, but they do not confirm all of the mtDNA clades, and there is conflict in some cases (e.g., all four N. sericea individuals have the same calmodulin allele, despite considerable mtDNA structure). Nuclear genes tend to evolve much more slowly than mtDNA, so considerable structure can appear in mitochondrial genes before concurrent changes occur in nDNA. Furthermore, the larger effective population sizes of nuclear genes mean that more time is needed for lineage sorting to become complete [26], so the lack of detailed structure in calmodulin and EF- $1 \alpha$ does not necessarily mean that the mtDNA clades are freely exchanging such genes. However, nuclear genes can also reveal sex-specific gene flow patterns that a uniparental marker like mtDNA can miss. The phylogeographic evidence of intraspecific diversification helps to alleviate the potential concern that, by sampling extensively "within species" for the BEAST analyses, we may be overestimating intraspecific sequence divergence and therefore the MRCA ages of the four species [27].

In NZ Kikihia and Maoricicada [16,28-30], mtDNA phylogeography and song patterns indicate Pleistoceneage allopatric diversification within currently recognized species. Populations with greater than $2.5 \%$ uncorrected mtDNA divergence frequently, although not always, exhibit discrete differences in song [16,29-31] - and in some cases conflicting patterns in EF-1 $\alpha$. The largest intraspecific mtDNA genetic distances within A. strepitans and $N$. sericea approach this threshold. We have not observed regional differences in the songs of Amphipsalta and Notopsalta during field collection and observation, but detailed examination might uncover minor variation concordant with the mtDNA tree.

The GMYC analysis (Additional file 1: Figure S1), which was intended to identify the shift from betweento within-population branching patterns [32], yielded results consistent with the inference that some of the geographically coherent mtDNA phylogroups are independently evolving populations. However, the large number of clades inferred for A. zelandica is surprising give the low sequence divergence within that species, and the GMYC results changed substantially when only $N$. sericea and $A$. strepitans haplotypes were examined. It is possible that the marginal statistical significance observed in the latter test is a sign of too little data for effective estimation of branching-rate shifts despite the likely existence of several independently evolving populations within these taxa.

If the mtDNA clades represent independently evolving subspecific populations, then at least 2-5 allopatric population-lineages per species have formed in Amphipsalta-Notopsalta during the Pleistocene, a rapid 
rate compared to the Late Miocene and Pliocene. This contrasts with the results from Kikihia, where the rate of population-lineage formation has remained approximately constant since the early Pliocene [1].

\section{Potential drivers of intraspecific divergence in Amphipsalta-Notopsalta Limited phylogeographic structure in forest taxa}

The low level of intraspecific genetic divergence characterizing Amphipsalta cingulata and A. zelandica is consistent with their dependence on temperate forest habitat. NZ forests progressively declined in extent throughout the Pleistocene, especially during the last million years. During the LGM $(\sim 22 \mathrm{ka})$, the principal forest refugia were located in northern NI and/or northwestern SI [33-35], with smaller fragments located farther south [36]. Roughly similar regions were predicted for $A$. zelandica refugia ( $A$. cingulata refugia were not successfully reconstructed). Both $A$. cingulata and A. zelandica contain haplotype clusters consistent with survival during the LGM in as few as two locations, one more northern and one more southern [37]. However, the phylogeographic structure observed within A. zelandica is insufficiently detailed to confirm the ENM predictions of two major refugia in NI and 2-3 in SI, although the genetic data are consistent with the absence of refugia in central or southern SI.

The lack of structure within A. zelandica is remarkable when compared with phylogenetic patterns observed in other forest species believed to have survived in SI [31,38-40]. While NZ forest taxa often show evidence of geographic restriction during the LGM, different species exhibit phylogeographic variation that likely relates to differences in life-history parameters or habitat specialization. For example, forest taxa including beetles [39-41] and a fern [42] appear to have survived glacial cold phases in small forest fragments in southern NZ and retained considerable phylogeographic structure there. In contrast, the only other widespread NZ forest cicada, Kikihia subalpina, retains considerable geographic structure on NI (where it lives mainly in subalpine scrub), but limited structure on SI where it inhabits lowland forest [31]. Greater Pleistocene stability of NI habitats has been linked to persistence of beetle species (as inferred from fossils; [43]). It is possible that, for cicadas, additional factors are needed to explain why the forest taxa have been unable to survive in southern NZ during colder climate phases (see also [41]).

Because the intraspecific lineages within A. zelandica and $A$. cingulata were inferred to coalesce around 370 ky and $160 \mathrm{ky}$, respectively, both species were likely limited to a single refugium during the Late Pleistocene. Some support for this idea is observed in climate proxies that suggest, around $430 \mathrm{ky}$, a glacial cold period that may have been more severe than the LGM $[44,45]$. Coalescence of regional clades around $430 \mathrm{ky}$ was also observed in Maoricicada campbelli [29]. This hypothesis could be tested more effectively by multi-gene datasets allowing more sensitive estimates of divergence times.

Dispersal ability may also have influenced population genetic structure in the Amphipsalta-Notopsalta species, contributing to lower genetic differentiation in the forest taxa A. zelandica and A. cingulata. Lineage-specific differences in traits affecting dispersal and gene flow should influence relative rates of allopatric divergence, especially in neutral genetic characters [46,47]. The two forest taxa are the largest-bodied cicadas in New Zealand (see photo inset in Figure 5), and they are likely the strongest fliers, suggesting that greater dispersal ability leads to greater gene flow among populations and reduced rates of allopatric differentiation in these species. However, the mtDNA data show that dispersal in A. cingulata and A. zelandica has not completely prevented the formation of intraspecific phylogeographic structure (Table 2, Figure 3 and Figure 5). All cicadas spend multiple years as juveniles underground, a lifehistory feature that must reduce population vagility compared to similarly sized insects [48].

\section{Mid-Pleistocene diversification of open-habitat species}

In Notopsalta sericea and Amphipsalta strepitans, more intraspecific lineages are evident than in the two forest taxa, and multiple lineages apparently persisted through the hypothesized Pleistocene minimum of $430 \mathrm{ky}$. In both cases, the credible intervals on mtDNA coalescence include the period from about 0.6-2.0 Ma (mean 1.4 and 1.2 Ma, respectively) (Table 3 ).

Multiple geological and climatic changes are known to have occurred around $1 \mathrm{Ma}$ that could have affected diversification of these open-habitat species [49]. Pleistocene climates became progressively colder and drier, suggesting the continued replacement of forests by shrub and grassland habitats. Large sections of NI and northern SI began a period of accelerated uplift that has continued to the present $[49,50]$, increasing rain shadow effects across eastern provinces and expanding the dry slope habitats used by $A$. strepitans and $N$. sericea. The puzzling mtDNA homogeneity of $N$. sericea populations across the northern third of NI, a reversal of the "northern richness, southern purity" pattern frequently observed in NZ [51-55], could be explained by very recent acceleration of uplift in that area [56] leading to northward dispersal from source populations in central NI.

Unlike $A$. zelandica and other forest insects whose LGM distributions have been modeled [39,40,52,55], for A. strepitans the hypothesized LGM range was not smaller than the present-day range (Figure 6). A higher degree of phylogeographic structuring relative to the 
other cicadas was also detected, consistent with survival of multiple distinct populations over a longer period, as has been detected in other non-forest invertebrates (e.g., [46,57-59]). A. strepitans was the only cicada for which temperature explained less than $15 \%$ of model fit, suggesting its wider LGM distribution may have been related to success in cooler temperatures, although tolerance of aridity could also be involved. Greater success in drier climates was offered to explain a larger LGM distribution implied by microsatellite data for the NZ tree species Pseudopanax ferox [60]. The ENM failed to capture the southern extent of A. strepitans' current distribution, possibly because of the low number of localities from South Canterbury and Otago relative to the wellsampled northeastern SI, limiting the inferences we can make about the LGM projection. However, the low sample numbers in the south likely indicate genuine scarcity in this region, and the discovery of additional southern localities would likely expand, rather than contract, the projected climatic distribution of this species.

\section{Ecological niche models and LGM refugia}

No LGM refugia were projected for $N$. sericea or $A$. cingulata, despite apparently successful model performance, implying that no counterpart of either species' current realized niche existed during the LGM. Yet genetic patterns suggest that both species survived on NI during that period, and $N$. sericea contains considerable mtDNA phylogeographic structure on NI. Three hypotheses (which are not mutually exclusive) can explain these surprising results: 1 ) the species have only recently occupied their current climatic niche (niche evolution), 2) they survived in isolated microrefugia undetectable using these methods, or 3) their current realized niches inadequately represent the fundamental niche of each species (environmental disequilibrium). The first hypothesis is less likely; existing evidence for insects, while largely based on beetles, offers little evidence of post-LGM shifts in climate exploitation [61,62].

The second and third hypotheses are both plausible, but difficult to disentangle. Amphipsalta cingulata and Notopsalta sericea survived somewhere in NZ, and it is likely that local habitat attributes created small refugia undetectable using our elevation-scaled meteorological data [63]. Past climates may have had different combinations of environmental variables than exist today, yielding predictions of past ranges that are under- or overestimates [31,64]. In addition, ENMs as applied here are a representation of each species' climatic niche, but if a species is restricted from exploiting its full climatic niche due to other factors, projections onto past climates may exclude potentially habitable areas [64]. Several cicada species are present in the southernmost NI but are absent from SI (see maps in [1]), indicating that
Cook Strait is an important dispersal barrier even for flighted species [31], and the absence of $A$. cingulata and $N$. sericea from cooler and wetter conditions in SI would result in underrepresentation of suitable LGM refugia. Excluding these potentially habitable, unoccupied regions from the training data reduces the risk of over-fitting but increases model uncertainty (clamping; [65]) and thus, transferability of the model [66], and for both species, restricting the training data resulted in clamping (extensively so for $N$. sericea) where none was previously detected. Interestingly, neither species has extended its range into the cooler mid- or high elevations of NI, and restricting the training data failed to yield additional refugia, suggesting that spurious over-fitting of the climate data was not the key driver of this absence, although it cannot be conclusively ruled out. Projections of ENMs onto past climates must be interpreted with caution, particularly where their congruence with external data (e.g., DNA) is low.

\section{Conclusions}

This study and others (e.g., [41]) show that closely related and regionally co-occurring organisms can experience dramatically different diversification rates over a substantial period (here, mid-Miocene to present), a conclusion presaged by earlier literature on species distributions (e.g., [67]). Because the two NZ cicada lineages colonized the landscape independently, the difference in the number of extant species is not simply a side-effect of the geography of initial diversification, as is possible with sister-clades [68]. Apparently, many physiological, ecological, and historical factors interact to influence diversification. In the case of the two NZ cicada radiations, we speculate that differences in climatic tolerances/ preferences of the two ancestors could have persistently influenced the geographic ranges of the two radiating lineages. Climatic refugia were not detected for two of the four species, suggesting that Pleistocene survival and lineage diversification were moderated by factors other than broad regional climatic conditions. This study also adds to a growing number of phylogeographic analyses implicating mountain-building and Pleistocene habitat fragmentation as drivers of diversification in NZ insects.

\section{Methods}

\section{Sample collection and range estimation}

Amphipsalta and Notopsalta specimens (typically male) were collected during surveys from 1993-2010. The species Kobonga apicata (Ashton) (see [69]), from central and western Australia, was selected as an outgroup based on phylogenetic analyses at the tribe level (unpublished data). Tissue collections were sought from sites distributed as uniformly as possible within each species' range. When a species was detected but not collected, 
the presence of its diagnostic song was noted and digitally recorded if possible. Localities used for ecological niche modeling were based on collection and song data from this study and historical records [11] (Figure 2; see Additional file 2: Appendix for details).

\section{Genetic sequencing}

Genomic DNA was extracted from 1-2 legs using the Qiagen DNeasy Tissue Kit and protocol (Qiagen, Valencia, California, USA), except that the digestion was conducted over 3-18 hours at $54{ }^{\circ} \mathrm{C}$. Approximately 1350 base pairs of the mitochondrial cytochrome oxidase I (COI) gene were amplified in one of two ways: (1) in two sections; the 5' (barcoding) section with primers C1-J-1490 + C1-N-2198 [70], annealing temperature $50^{\circ} \mathrm{C}$, and the $3^{\prime}$ section with primers C1-J-2195 + TL2-N3014 [71], annealing temperature $56^{\circ} \mathrm{C}$; (2) in one piece using C1-J-1490+ TL2-N-3014, annealing temperature $45^{\circ} \mathrm{C}$. Amplified products were cleaned using the Clontech Extract II Kit (Clontech, Mountain View, CA, USA) or ExoSAP-IT (USB Corp., Cleveland, OH). For examination of the species-level Amphipsalta-Notopsalta relationships, a subset (see Additional file 2: Appendix) of the individuals sampled were sequenced for two nuclear genes, Calmodulin (763 bp) and elongation factor-1 alpha (EF-1 $\alpha$; ca. 1400 bp). Calmodulin was amplified using the primers Cal60For [16] and Cal2Rev (UBC insect primer kit). A touchdown cycle was used with the following parameters: (1) a $94^{\circ} \mathrm{C}$ hold for 2 min.; (2) a touchdown PCR sequence of $94^{\circ} \mathrm{C}$ for $45 \mathrm{sec}$., $60-50^{\circ} \mathrm{C}$ for $45 \mathrm{sec}$., and $72^{\circ} \mathrm{C}$ for $1 \mathrm{~min}$. - decreasing by $1^{\circ} \mathrm{C}$ every cycle and repeated for 10 cycles; (3) a steady PCR sequence of $94^{\circ} \mathrm{C}$ for $45 \mathrm{sec}$., $50^{\circ} \mathrm{C}$ for $45 \mathrm{sec}$., and $72^{\circ} \mathrm{C}$ for $1 \mathrm{~min}$., repeated for 25 cycles; and (4) a $72^{\circ} \mathrm{C}$ hold for $10 \mathrm{~min}$. For A. cingulata, internal calmodulin primers were created from the sequence of the other cicadas. EF- $1 \alpha$ was amplified in two overlapping sections using the primers EF1-F001cicada + EF1-R752 [5], annealing temperature $53^{\circ} \mathrm{C}$, and EF1-PA-f650ambig [72] + EF1-N-1419 [73], annealing temperature $58^{\circ} \mathrm{C}$. Cycle sequencing was conducted using the Applied Biosystems Big Dye Terminator v1.1 cycle sequencing kit at 1/8- to $1 / 4$-scale reaction volume, and the product was cleaned by Sephadex filtration (GE Healthcare, Piscataway, NJ, USA) and visualized on an Applied Biosystems ABI 3100 capillary sequencer. Sequences were analyzed using ABI Prism Sequencing Analysis software v3.7 (Applied Biosystems), edited in Sequencher v3.1 (Gene Codes Corp., Ann Arbor, MI), aligned in MacClade [74] and checked by eye.

\section{Phylogenetic estimation}

Individual gene-trees were estimated using partitioned maximum-likelihood (ML) in Garli version 2.0 [75], using datasets that contained all unique haplotypes. Each nuclear gene was modeled using a single partition because of the low number of parsimony-informative sites available for estimating parameters (see Results); substitution models for these genes were selected using Modeltest v3.7 [76]. For the mtDNA data, alternative combinations of partition schemes and partition-specific substitution models, based on the three codon-position categories, were tested using the "greedy" algorithm of the program PartitionFinder v1.0 [77] and the BIC criterion, with the branch lengths of alternative partitions linked and with the software set to evaluate the full substitution model set. Default settings were used for Garli analyses, except that the number of generations required for termination (genthreshfortopoterm) was increased to 40,000 to improve the search. ML analyses in Garli offered estimates of branch lengths that were not influenced by Bayesian priors [78,79]. The number of discrete gamma categories was set to 8 to improve resolution of site rates over the default setting of 4 categories. For each analysis, 100 bootstrap pseudoreplicates were conducted in Garli, and these were summarized on the ML tree with the program SumTrees v3.3.1, part of the DendroPy package [80].

\section{Pairwise genetic divergence plots}

Because "saturation" of genetic data by multiple hits has been observed to influence divergence time estimates $[81,82]$, we constructed plots of uncorrected genetic distances calculated in Mesquite v. 2.75 [83] vs. ML model-corrected patristic (tree-based) distances for the Amphipsalta-Notopsalta COI dataset and a published, combined COI + COII ingroup dataset of about the same size (bp) from Kikihia [1] containing 30 species. Maximum uncorrected genetic distances from the Kikihia dataset are similar to those in Amphipsalta-Notopsalta.

\section{Divergence-time estimation}

To place the Amphipsalta-Notopsalta tree in an approximate time frame, Bayesian relaxed-clock phylogenetic analyses of the full COI dataset, with identical haplotypes and the outgroup included, were conducted using BEAST v1.6.1 [84]. Because no fossil or geological calibrations are available for dating these cicadas, the analysis was calibrated using COI molecular clock estimates from the literature. While many insect studies have used the 0.0115 substitutions/site/my/lineage clock rate estimated by Brower [17], more recent studies have suggested both lower (e.g., [19,85]) and higher rates [25] (Table 5), in part because of the use of highly partitioned sequence-evolution models [25] that tend to reconstruct more change along branches. In each analysis, the mean and standard deviation of the relaxed clock were fixed to reflect the literature estimates from Table 5 by the following settings: (1) we set ucld.mean (the mean of the 
lognormal prior distribution on branch rates) to 0.0115 substitutions/site/my, the Brower [17] rate, (2) we set ucld.stdev, the standard deviation of the lognormal prior on branch rates, to 0.3 , so that the $95 \%$ confidence interval of the lognormal distribution included rates from 0.006 to 0.0188 substitutions/site/my, and (3) we deactivated the operators for ucld.mean and ucld.stdev, so that the software did not attempt to estimate these parameters. We suggest that the approach of combining all empirical knowledge into a single prior is superior to the use of separate analyses under alternative rates an approach that was used in earlier work on Kikihia [1].

BEAST analyses of the COI dataset used the same three-partition scheme as the ML analysis. The Amphipsalta sequences were constrained to form a monophyletic clade, as supported by the ML analysis (see Results), because initial runs of some models suggested a tendency for BEAST to place the ingroup root between clades containing $A$. cingulata $+A$. zelandica and $N$. seri$c e a+A$. strepitans. Model parameters and partition rate multipliers were estimated separately for each partition. Four tree priors were tested in separate analyses and compared using the Bayes factor scores calculated in Tracer v1.5 [86]: Yule, birth-death, a constant-size coalescent, and an expansion-growth coalescent. The criterion $2 \ln$ Bayes factor $>10$ [87] was used to decide if a given model was superior. Models were run to 40 million generations, and stationarity and adequate sample sizes (i.e., > 200) were confirmed using Tracer [86] and by ensuring that multiple runs found the same solution. Other priors were left at the default values specified by BEAUti v 1.6.1 (provided with the BEAST package). Statistically improper priors, such as intervals extending to infinity, were converted to proper priors with a large, finite upper bound. Prior distributions were estimated by running the analysis with no data.

\section{Test for intraspecific diversification}

Because phylogeographic patterns in the mtDNA dataset suggested ongoing intraspecific allopatric diversification, we tested for the threshold between interspecific and intraspecific lineage dynamics using the generalized mixed Yule-coalescent (GMYC) model of Pons et al. [32] as implemented in the $\mathrm{R}$ package SPLITS [88,89]. If the samples of each species are drawn from a single panmictic population, the method should identify a branching-rate shift at the base of each species caused by the change from coalescent (intraspecific) to birthdeath (interspecific) dynamics. A tree containing only unique haplotypes was analyzed in BEAST to obtain a chronogram under the same model used in the divergence-time analysis above. The chronogram was tested in the GMYC analysis using an interval of 0,10 and a single-threshold model.
Geographic structure in the mtDNA dataset was also tested using an analysis of molecular variance (AMOVA) as implemented in Arlequin v 3.1 [90]. Populations were combined into groups according to a six-region scheme defined by Cook Strait and latitude lines $-37^{\circ} \mathrm{S},-39^{\circ} \mathrm{S}$, $-43^{\circ} \mathrm{S}$, and $-45^{\circ} \mathrm{S}$.

\section{Ecological niche modeling}

Combining ecological niche models with paleoclimatic data to hindcast species ranges offers a means of testing refugia hypotheses developed from genetic information. For comparison with intraspecific phylogeographic patterns, the current and LGM distributions of each species were estimated using ecological niche models. Climate data used to construct the ENMs included mean annual rainfall $(\mathrm{mm})$, mean February rainfall $(\mathrm{mm})$, mean annual solar radiation $\left(\mathrm{kJ} /\right.$ day $\left./ \mathrm{m}^{2}\right)$, mean annual temperature $\left({ }^{\circ} \mathrm{C}\right)$, mean February temperature $\left({ }^{\circ} \mathrm{C}\right)$, minimum temperature of the coldest month $\left({ }^{\circ} \mathrm{C}\right.$, July), and October vapor pressure deficit $(\mathrm{kPa})$, all at $100 \mathrm{~m}$ resolution [91]. These layers, derived from meteorological data (19501980, [91]), were fitted to the LGM based on estimates of temperature depression from marine isotope stages and estimates of LGM topography based on depression of the sea level by $120 \mathrm{~m}$ (J.R. Leathwick, unpublished data, see [39]).

Ecological niche models were generated with Maxent 3.3.1 [92,93]. Models were built using 341 A. zelandica, 62 A. strepitans, 86 A. cingulata and 87 Notopsalta sericea localities. Maximum iterations were increased as necessary to allow the algorithm to converge, with default settings used otherwise. To ensure consistency of model predictions among repeated runs, we performed a 10 -fold cross-validation, in which a different $90 \%$ of localities were used to train the model and $10 \%$ were used to test it for each of 10 runs, such that each locality was used to test the model once. Estimated models for each species were projected onto LGM climate surfaces for all 10 runs, using the "fade by clamping" setting for output grids, to visually inspect for differences in regions projected as suitable habitat between replicate runs. "Clamping" refers to the handling of LGM grid sections with climatic values outside the range observed during training - Maxent sets these to the corresponding maximum or minimum observed training value. The "fade by clamping" method attempts to correct for the effect of this uncertainty on the projected distribution by reducing the estimated climatic suitability proportional to the level of clamping. Clamping grids were also inspected for differences in model output under different data partitions. The final geographical projections represent the mean point-wise prediction over ten model runs. Model performance was evaluated using thresholddependent binomial omission tests and the Area Under 
the (Receiver Operating Characteristic) Curve (AUC) calculated by Maxent.

Regions which contain suitable climate conditions for a species may be unoccupied due to other factors, such as dispersal barriers [94]. Inclusion of these regions during model calibration can result in overfitting to conditions found near the collection localities [65]. When hindcasting to LGM climate conditions indicated no refugia for the two taxa limited to NI (A. cingulata and $N$. sericea; see below), we re-ran these analyses using NI climate data only for training and testing to examine whether the model for these species was being overfitted by the inclusion of SI data. The model was then projected onto LGM surfaces for all of NZ. While Cook Strait is not likely to be an absolute dispersal barrier to cicadas, it could delay colonization of SI by species restricted to northern NI refugia.

\section{Additional files}

Additional file 1: Figure S1. Population-lineages diagnosed within the four described species using the generalized mixed Yule-coalescent algorithm. Connected red branches indicate haplotypes contained within a single diagnosed population. Results varied considerably depending on the particular tree used (e.g., all sequences, haplotypes only, A. strepitans$N$. sericea only) but multiple lineages were always detected within the four described species.

Additional file 2: Appendix Specimen locality data. Asterisked latitude indicates that GPS was estimated from a printed map. Elevations were recorded in meters.

\section{Competing interests}

All authors declare that no competing financial or non-financial interests exist.

\section{Authors' contributions}

DM collected specimens, conceived the study, conducted phylogenetic and phylogeographic analyses, and drafted the manuscript. KH collected specimens, conceived the study, conducted genetic sequencing, and drafted the manuscript. KM conceived the study, conducted the ENM analyses and drafted the manuscript. CC conducted genetic sequencing and assisted with phylogenetic and phylogeographic analyses. TB collected specimens, assisted with the analyses, and drafted the manuscript. CS collected specimens, conceived and coordinated the study and its funding, assisted with the analyses, and drafted the manuscript. All authors read and approved the final manuscript.

\section{Acknowledgments}

The authors thank Craig Briggs, Robbie Price, Gary Barker, and David NoguésBravo for assistance with the climatic data and ecological niche models. Field work assistance and local knowledge were contributed by Peter Arensburger, Steve Chiswell, John Cooley, John Dugdale, George Gibbs, Kees Green, Chris Owen, David Lane, Ricardo Palma, Dan Vanderpool, and Beth Wade. NZ Dept. of Conservation (lan Millar, Bev Freer and numerous field staff), the National Museum of NZ (Te Papa) and the National Insect Collections contributed permits and expertise. Anne Firnan, Peter Hill, and Barbara Hill allowed access to private land. The shaded elevation map was provided by Roger Smith of www.geographx.co.nz. KAM acknowledges the Danish National Research Foundation for support to the Center for Macroecology, Evolution and Climate. TRB and KAM were funded by the Royal Society of New Zealand Marsden Fund (LCR0502) and the Ministry of Science and Innovation through the Defining New Zealand's Land Biota programme. Computational resources were provided by Bioportal at the University of Oslo (http://www.bioportal.uio.no). This material is based upon work partially supported by the National Science Foundation under Grants No. DEB 04-22386, DEB 05-29679, DEB 07-20664, and DEB 09-55849. Any opinions, findings, and conclusions or recommendations expressed in this material are those of the authors and do not necessarily reflect the views of the NSF.

\section{Author details}

${ }^{1}$ Department of Ecology and Evolutionary Biology, University of Connecticut, 75 N. Eagleville Rd, Storrs, CT 06269, USA. ²Center for Macroecology, Evolution and Climate, University of Copenhagen, Copenhagen, Denmark. ${ }^{3}$ Landcare Research, Private Bag 92170, Auckland, New Zealand. ${ }^{4}$ School of Biological Sciences, The University of Auckland, Private Bag 92019, Auckland, New Zealand. ${ }^{5}$ Allan Wilson Centre for Molecular Ecology and Evolution, Auckland, New Zealand. ${ }^{6}$ School of Biological Sciences, Victoria University of Wellington, Wellington, New Zealand.

Received: 24 December 2011 Accepted: 15 August 2012 Published: 11 September 2012

\section{References}

1. Marshall DC, Slon K, Cooley JR, Hill KBR, Simon C: Steady Plio-Pleistocene diversification and a 2-million-year sympatry threshold in a New Zealand cicada radiation. Mol Phylogenet Evol 2008, 48:1054-1066.

2. Buckley TR, Simon C: Evolutionary radiation of the cicada genus Maoricicada Dugdale (Hemiptera: Cicadoidea) and the origins of the New Zealand alpine biota. Biol J Linn Soc 2007, 91:419-435.

3. Simon C: Using New Zealand examples to teach Darwin's "Origin of Species:" Lessons from molecular phylogenetic studies of cicadas. NZ Sci Rev 2009, 66:102-112.

4. Buckley TR, Arensburger P, Simon C, Chambers GK: Combined data, Bayesian phylogenetics, and the origin of the New Zealand Cicada genera. Syst Biol 2002, 51:4-18.

5. Arensburger P, Buckley TR, Simon C, Moulds M, Holsinger KE: Biogeography and phylogeny of the New Zealand cicada genera (Hemiptera: Cicadidae) based on nuclear and mitochondrial DNA data. J Biogeogr 2004, 31:557-569.

6. Fleming CA: A new species of cicada from rock fans in southern Wellington, with a review of three species with similar songs and habitat. NZ J Sci 1971, 14:443-479.

7. Fleming CA: Adaptive radiation in New Zealand cicadas. Proc Am Phil Soc 1975, 119:298-306.

8. Fleming CA: The cicada genus Kikihia (Dugdale) (Hemiptera, Homoptera). Part 1. The New Zealand green foliage cicadas. Nat Mus NZ Rec 1984, 2:191-206.

9. Dugdale JS, Fleming CA: New Zealand cicadas of the genus Maoricicada (Homoptera: Tibicinidae). NZ J Zool 1978, 5:295-340.

10. Arensburger $P$, Simon $C$, Holsinger K: Evolution and phylogeny of the New Zealand cicada genus Kikihia Dugdale (Homoptera: Auchenorrhyncha: Cicadidae) with special reference to the origin of the Kermadec and Norfolk Islands' species. J Biogeogr 2004, 31:1769-1783.

11. Dugdale JS, Fleming CA: Two New Zealand cicadas collected on Cooks' Endeavour voyage, with description of a new genus. NZ J. Sci. 1969, 12:929-957.

12. Hudson GV: Fragments of New Zealand Entomology. Wellington, New Zealand: Ferguson and Osborn; 1950.

13. Myers JG: Insect singers: a natural history of the cicadas. London: George Routledge and Sons; 1929.

14. Cooper RA, Millener PR: The New Zealand biota: Historical background and new research. Tr Ecol Evol 1993, 8:429-433.

15. Wallis GP, Trewick SA: New Zealand phylogeography: evolution on a small continent. Mol Ecol 2009, 18:3548-3580.

16. Buckley TR, Cordeiro M, Marshall DC, Simon C: Differentiating between hypotheses of lineage sorting and introgression in New Zealand alpine cicadas (Maoricicada Dugdale). Syst Biol 2006, 55:411-425.

17. Brower AVZ: Rapid morphological radiation and convergence among races of the butterfly Heliconius erato inferred from patterns of mitochondrial DNA evolution. Proc Natl Acad Sci USA 1994, 91:6491-6495.

18. Knowlton N, Weight LA, Solorzano LA, Mills DK, Bermingham E: Divergence in proteins, mitochondrial DNA, and reproductive compatibility across the Isthmus of Panama. Science 1993, 260:1629-1632. 
19. Farrell BD: Evolutionary assembly of the milkweed fauna: cytochrome oxidase I and the age of Tetraopes beetles. Mol Phylogenet Evol 2001, 18:467-478

20. Knowlton N, Weigt LA: New dates and new rates for divergence across the Isthmus of Panama. Proc Roy Soc Biol Sci B 1998, 265:2257-2263.

21. Buckley TR, Simon C, Chambers GK: Exploring among-site rate variation models in a maximum likelihood framework using empirical data: effects of model assumptions on estimates of topology, branch lengths, and bootstrap support. Syst Biol 2001, 50:67-86.

22. Sullivan J, Joyce P: Model selection and phylogenetics. Annu Rev Ecol Syst 2005, 36:445-466.

23. Simon C, Buckley TR, Frati F, Stewart JB, Beckenbach AT: Incorporating molecular evolution into phylogenetic analysis, and a new compilation of conserved polymerase chain reaction primers for animal mitochondrial DNA. Annu Rev Ecol Evol Syst 2006, 37:545-579.

24. Venditti C, Meade A, Pagel M: Detecting the node-density artifact in phylogeny reconstruction. Syst Biol 2006, 55:637-643.

25. Papadopoulou A, Anastasiou I, Vogler AP: Revisiting the insect molecular clock: The mid-Aegean trench calibration. Mol Biol Evol 2010, 27:1659-1672

26. Moore WS: Inferring phylogenies from mtDNA variation: mitochondrialgene trees versus nuclear-gene trees. Evolution 1995, 49:718-726.

27. Ho SYW, Saarma U, Barnett R, Haile J, Shapiro B: The effect of inappropriate calibration: three case studies in molecular ecology. PLOS One 2008, 3:e1615.

28. Buckley TR, Simon C, Chambers GK: Phylogeography of the New Zealand cicada Maoricicada campbelli based on mitochondrial DNA sequences: Ancient clades associated with Cenozoic environmental change. Evolution 2001, 55:1395-1407

29. Hill KBR, Simon C, Marshall DC, Chambers GK: Surviving glacial ages within the biotic gap: phylogeography of the New Zealand cicada Maoricicada campbelli. J Biogeogry 2009, 36:675-692

30. Marshall DC, Hill KBR, Cooley JR, Simon C: Hybridization, mitochondrial DNA taxonomy, and prediction of the early stages of reproductive isolation: Lessons from New Zealand cicadas of the genus Kikihia. Syst Biol 2011, 60:482-502.

31. Marshall DC, Hill KBR, Fontaine KM, Buckley TR, Simon C: Glacial refugia in a maritime temperate climate: Cicada (Kikihia subalpina) mtDNA phylogeography in New Zealand. Mol Ecol 2009, 18:1995-2009.

32. Pons J, Barraclough TG, Gomez-Zurita J, Cardoso A, Duran DP, Hazell S, Kamoun S, Sumlin WD, Vogler AP: Sequence-based species delimitation for the DNA taxonomy of undescribed insects. Syst Biol 2006, 55:595-609.

33. Marra MJ, Shulmeister J, Smith EGC: Reconstructing temperature during the Last Glacial Maximum from Lyndon Stream, South Island, New Zealand using beetle fossils and maximum likelihood envelopes. Quat Sci Rev 2006, 25:1841-1849.

34. Alloway BV, Lowe DJ, Barrell DJA, Newnham RM, Almond PC, Augustinius PC, Bertler NAN, Carter L, Litchfield NJ, McGlone MS, et al: Towards a climate event stratigraphy for New Zealand over the past 30,000 years (NZ-INTIMATE project). J Quat Sci 2007, 22:9-35.

35. Marra M, Leschen RAB: Late Quaternary paleoecology from fossil beetle communities in the Awatere Valley, South Island, New Zealand. J Biogeogr 2004, 31:571-586.

36. McGlone MS, Newnham RM, Moar NT: The vegetation cover of New Zealand during the Last Glacial Maximum: do pollen records underrepresent woody vegetation? Terra Australis 2010, 32:49-68.

37. Provan J, Bennett KD: Phylogeographic insights into cryptic glacial refugia. Tr Ecol Evol 2008, 23:564-571.

38. Boyer SL, Baker JM, Giribet G: Deep genetic divergences in Aoraki denticulata (Arachnida, Opiliones, Cyphophthalmi): a widespread 'mite harvestman' defies DNA taxonomy. Mol Ecol 2007, 16:4999-5016.

39. Marske KA, Leschen RAB, Barker GM, Buckley TR: Phylogeography and ecological niche modelling implicate coastal refugia and trans-alpine dispersal of a New Zealand fungus beetle. Mol Ecol 2009, 18:5126-5142.

40. Marske KA, Leschen RAB, Buckley TR: Reconciling phylogeography and ecological niche models for New Zealand beetles: Looking beyond glacial refugia. Mol Phylogenet Evol 2011, 59:89-102.

41. Marske KA, Leschen RAB, Buckley TR: Concerted versus independent evolution and the search for multiple refugia: comparative phylogeography of four forest beetles. Evolution 2011, 66:1862-1877.
42. Shepherd $L D$, Perrie $L R$, Brownsey PJ: Fire and ice: volcanic and glacial impacts on the phylogeography of the New Zealand forest fern Asplenium hookerianum. Mol Ecol 2007, 16:4536-4549.

43. Marra MJ, Leschen RAB: Persistence of New Zealand Quaternary beetles. N Z J Geol Geophys 2011, 54:403-413.

44. Carter RM: A New Zealand climatic template back to c. 3.9 Ma: ODP Site 1119, Canterbury Bight, south-west Pacific Ocean, and its relationship to onland successions. J Roy Soc N Z 2005, 35:9-42.

45. Zachos J, Pagani M, Thomas E, Billups K: Trends, rhythms, and aberrations in global climate 65 Ma to present. Science 2001, 292:689-693.

46. McCullough GA, Wallis GP, Waters JM: Do insects lose flight before they lose their wings? Population genetic structure in subalpine stoneflies. Mol Ecol 2009, 18:4073-4087.

47. Gillespie RG, Roderick GK: Arthropods on islands: colonization, speciation, and conservation. Annu Rev Entomol 2002, 47:595-632.

48. de Boer AJ, Duffels JP: Historical biogeography of the cicadas of Wallacea, New Guinea and the West Pacific: a geotectonic explanation. Palaeogeogr, Palaeoclimat, Palaeoecol 1996, 124:153-177.

49. Trewick SA, Bland KJ: Fire and slice: palaeogeography for biogeography at New Zealand's North Island/South Island juncture. J Roy Soc N Z 2011, 1-31. In press.

50. Bunce M, Worthy TH, Phillips MJ, Holdaway RN, Willerslev E, Haile J, Shapiro B, Scofield RP: The evolutionary history of the extinct ratite moa and New Zealand Neogene paleogeography. Proc Natl Acad Sci USA 2009, 106:20646-20651.

51. Gardner RC, De Lange PJ, Keeling DJ, Bowala T, Brown HA, Wright SD: A late Quaternary phylogeography for Metrosideros (Myrtaceae) in New Zealand inferred from chloroplast DNA haplotypes. Biol J Linn Soc 2004, 83:399-412.

52. Buckley TR, Marske K, Attanayake D: Phylogeography and ecological niche modelling of the New Zealand stick insect Clitarchus hookeri (White) support survival in multiple coastal refugia. J Biogeogr 2010, 37:682-695.

53. Chapple DG, Daugherty $\mathrm{CH}$, Ritchie PA: Comparative phylogeography reveals pre-decline population structure of New Zealand Cyclodina (Reptilia: Scincidae) species. Biol J Linn Soc 2008, 95:388-408.

54. Morgan-Richards M, Trewick SA, Wallis GP: Chromosome races with Pliocene origins: evidence from mtDNA. Heredity 2001, 86:303-312

55. Buckley TR, Marske KA, Attanayake D: Identifying glacial refugia in a geographic parthenogen using palaeoclimate mdeling and phylogeography: the New Zealand stick insect Argosarchus horridus (White). Mol Ecol 2009, 18:4650-4663.

56. Claessens L, Veldkamp A, Broeke EM, Vloemans H: A Quaternary uplift record for the Auckland region, North Island, New Zealand, based on marine and fluvial terraces. Global Planet Change 2009, 68:383-394.

57. Pons J, Fujisawa T, Claridge EM, Savill RA, Barraclough TG, Vogler AP: Deep mtDNA subdivision within Linnean species in an endemic radiation of tiger beetles from New Zealand (genus Neocicindela). Mol Phylogenet Evol 2010, 59:251-262.

58. O'Neill SB, Chapple DG, Daugherty CH, Ritchie PA: Phylogeography of two New Zealand lizards: McCann's skink (Oligosoma maccanni) and the brown skink (O. zelandicum). Mol Phylogenet Evol 2008, 48:1168-1177.

59. O'Neill SB, Buckley TR, Jewell TR, Ritchie PA: Phylogeographic history of the New Zealand stick insects Niveaphasma annulata (Phasmatodea) estimated from mitochondrial and nuclear loci. Mol Phylogenet Evol 2009 53:523-536.

60. Shepherd LD, Perrie LR: Microsatellite DNA analyses of a highly disjunct New Zealand tree reveal strong differentiation and imply a formerly more continuous distribution. Mol Ecol 2011, 20:1389-1400.

61. Marra MJ: Quaternary fossil beetles from New Zealand. N Z Entomol 2008, 31:5-16.

62. Elias S: Quaternary beetles and the environments. Washington, D.C: Smithsonian Institution Press; 1994.

63. Ashcroft MB: Identifying refugia from climate change. J Biogeogr 2010, 37:1407-1413

64. Varela S, Rodríguez J, Lobo JM: Is current climatic equilibrium a guarantee for the transferability of distribution model predictions? J Biogeogr 2009 , 36:1645-1655.

65. Anderson RP, Raza A: The effect of the extent of the study region on GIS models of species geographic distributions and estimates of niche evolution: preliminary tests with montane rodents (genus Nephelomys) in Venezuela. J Biogeogr 2010, 37:1378-1393. 
66. Thuiller $W L$, Brotons $L$, Araújo MB, Lavorel S: Effects of restricting environmental range of data to project current and future species distributions. Ecography 2004, 27:165-172.

67. Davis MB: Quaternary history of deciduous forests of eastern North American and Europe. Ann Missouri Bot Garden 1983, 70:550-563.

68. Pigot AL, Phillimore AB, Owens IPF, Orme CDL: The shape and temporal dynamics of phylogenetic trees arising from geographic speciation. Syst Biol 2010, 59:660-673.

69. Ashton JH: Catalogue of the Cicadidae in the South Australian museum with descriptions of several new species. Trans Proc R Soc $S$ Aust 1914, 38:345-358.

70. Folmer $\mathrm{O}$, Black M, Hoeh W, Lutz R, Vrijenhoek R: DNA primers for amplification of mitochondrial cytochrome c oxidase subunit I from diverse metazoan invertebrates. Mol Mar Biol Biotechnol 1994, 3:294-297

71. Simon C, Frati F, Beckenbach A, Crespi B, Liu H, Flook P: Evolution, weighting, and phylogenetic utility of mitochondrial gene sequences and a compilation of conserved PCR primers. Annals of the Entomological Society of America 1994, 87:651-701.

72. Lee YJ, Hill KBR: Systematic revision of the genus Psithyristria Stål (Hemiptera: Cicadidae) with seven new species and a molecular phylogeny of the genus and higher taxa. Systematic Entomology 2010, 35:277-305.

73. Sueur J, Vanderpool D, Simon C, Ouvrard D, Bougoin T: Molecular phylogeny of the genus Tibicina (Hemiptera, Cicadidae): rapid radiation and acoustic behaviour. Biol J Linn Soc 2007, 91:611-626.

74. Maddison DR, Maddison WP: MacClade 4: Analysis of phylogeny and character evolution. In Book MacClade 4: Analysis of phylogeny and character evolution. ed.^edsth edition. City: Sinauer Associates; 2000

75. Zwickl DJ: Genetic algorithm approaches for the phylogenetic analysis of large biological sequence datasets under the maximum likelihood criterion. The University of Texas: Ph. D; 2006

76. Posada D, Crandall KA: Modeltest: testing the model of DNA substitution. Bioinformatics 1998, 14:817-818.

77. Lanfear R, Calcott B, Ho SYW, Guindon S: PartitionFinder: combined selection of partitioning schemes and substitution models for phylogenetic analyses. Mol Biol Evol 2012, 29:1695-1701.

78. Marshall DC: Cryptic failure of partitioned Bayesian phylogenetic analyses: lost in the land of long trees. Syst Biol 2010, 59:108-117.

79. Brown J, Hedtke SM, Lemmon AR, Lemmon EM: When trees grow too long: Investigating the causes of highly inaccurate Bayesian branchlength estimates. Syst Biol 2010, 59:145-161.

80. Sukumaran J, Holder MT: DendroPy: a Python library for phylogenetic computing. Bioinformatics 2010, 26:1569-1571.

81. Brandley MC, Wang Y, Guo X, de Oca ANM, Feria-Ortiz M, Hikida T, Ota H: Accommodating heterogeneous rates of evolution in molecular divergence dating methods: an example using intercontinental dispersal of Pleistodon (Eumeces) lizards. Syst Biol 2011, 60:3-15.

82. Phillips MJ: Branch-length estimation bias misleads molecular dating for a vertebrate mitochondrial phylogeny. Gene 2009, 441:132-140.

83. Maddison WP, Maddison DR: Mesquite: a modular system for evolutionary analysis. Version 2.75. http://mesquiteproject.org. In Book Mesquite: a modular system for evolutionary analysis. 275th edition. City: 2011. Version 2.75. http://mesquiteproject.org.

84. Drummond AJ, Rambaut A: BEAST: Bayesian evolutionary analysis by sampling trees. BMC Evol Biol 2007, 7:214.

85. Sota T, Hayashi M: Comparative historical biogeography of Plateumaris leaf beetles (Coleoptera: Chrysomelidae) in Japan: interplay between fossil and molecular data. J Biogeogr 2007, 34:977-993.

86. Rambaut A, Drummond AJ: Tracer v1.3. Available from http://evolve.zoo.ox. ac.uk/.

87. Kass RE, Raftery AE: Bayes factors. J Am Stat Assoc 1995, 90:773-795.

88. SPLITS: SPecies Limits by Threshold Statistics, v. 1.0-11. Available from http:// barralab.bio.ic.ac.uk/downloads.html.

89. R Development Core Team: $R$ : A language and environment for statistical computing. Vienna, Austria: R Foundation for Statistical Computing; 2011

90. Excoffier L, Laval G, Schneider S: Arlequin (ver. 3.0): an integrated software package for population genetics data analysis. Evol Bioinform Online 2005, $1: 47-50$.
91. Leathwick J, Morgan F, Wilson G, Rutledge D, McLeod M, Johnston K: Land Environments of New Zealand Technical Guide. Auckland, New Zealand: David Bateman Ltd.; 2003.

92. Phillips SJ, Anderson RP, Schapire RE: Maximum entropy modeling of species geographic distributions. Ecol Model 2006, 190:231-259.

93. Phillips SJ, Dudík M: Modeling of species distributions with Maxent: new extensions and a comprehensive evaluation. Ecography 2008, 31:161-175.

94. Pearson RG, Dawson TP: Predicting the impacts of climate change on the distribution of species: are bioclimate envelope models useful? Glob Ecol Biogeogr 2003, 12:361-371.

95. Caccone A, Sbordoni V: Molecular biogeography of cave life: a study using mitochondrial DNA from Bathysciine beetles. Evolution 2001, 55:122-130.

96. Juan C, Oromi P, Hewitt GM: Mitochondrial phylogeny and sequential colonization of Canary Islands by darkling beetles of the genus Pimelia. Proc Royal Soc Biol Sciences Series B 1995, 261:173-180.

97. Morrison $C L$, Ríos R, Duffy JE: Phylogenetic evidence for an ancient rapid radiation of Carribean sponge-dwelling snapping shrimps. Mol Phylogenet Evol 2004, 30:563-581.

98. Schubart CD, Diesel R, Hedges SB: Rapid evolution to terrestrial life in Jamaican crabs. Nature (London) 1998, 393:363-365.

doi:10.1186/1471-2148-12-177

Cite this article as: Marshall et al:: Limited, episodic diversification and contrasting phylogeography in a New Zealand cicada radiation. BMC Evolutionary Biology 2012 12:177.

\section{Submit your next manuscript to BioMed Central and take full advantage of:}

- Convenient online submission

- Thorough peer review

- No space constraints or color figure charges

- Immediate publication on acceptance

- Inclusion in PubMed, CAS, Scopus and Google Scholar

- Research which is freely available for redistribution 